\title{
Caracterização de uma nova mutação com perda de função do gene Krmt2d em camundongos
}

\section{Characterization of a new mutation with loss of function in the Kmt2d gene in mice}

\section{Resumo}

O camundongo mutante recessivo bate-palmas (bapa) originou-se de mutagênese química induzida por ENU ( $\mathrm{N}$-ethyl-N-nitrosourea) e apresenta alterações posturais com movimentos anormais dos membros posteriores quando levantado pela cauda. No sequenciamento do exoma identificou-se uma mutação no gene $\mathrm{Kmt2d}$, localizado no cromossomo 15, que foi confirmada pelo sequenciamento do DNA pelo método de Sanger. A perda da função do gene KMT2D localizada no cromossomo 12 em humanos foi descrita como responsável pela síndrome de Kabuki, que é uma anomalia congênita rara, autossômica dominante. O fenótipo clínico da doença é variável, mas algumas características mais comuns são face dismórfica, anormalidades esqueléticas, alterações nas impressões digitais, leve a moderado retardo mental e retardo do crescimento pós-natal. O presente trabalho teve como objetivo a análise do comportamento e da morfologia craniofacial dos camundongos bapa comparando com modelos de mutação do gene Kmt2d descritos na literatura.

Projeto aprovado pela CEUA FMVZ protocolo n. 1004070715. Apoio Financeiro: FAPESP processo 2016/23659-6

\section{Abstract}

The recessive mutant mouse named bate-palmas (bapa) - claps in Portuguese, originates from an ENU ( $\mathrm{N}$-ethyl-N-nitrosourea) mutagenesis program, presenting balance impairment and motor incoordination. Exome sequencing identified a mutation in the KMT2D gene, located on chromosome 15, which was confirmed by DNA sequence by the Sanger method. The loss of function of the gene KMT2D, located on chromosome 12 in humans, was described as being responsible for Kabuki syndrome, also known as Niikawa-Koruki syndrome, which is a rare congenital anomaly, autosomal dominant. The clinical phenotype of the disease is variable, but some common characteristics are dysmorphic facial features, skeletal abnormalities, fingerprint alterations, mild to moderate cognitive problems and postnatal growth retardation. The objective os this study was to analyze the behavior and craniofacial morphology of bapa mice comparing to KMT2D gene mutation models described on literature.

Project approved by CEUA FMVZ, protocol no. 100407015. Financial support: FAPESP process 2016/23659-6 
Pedro Kenzo Yamamoto ${ }^{1}$

Nicássia Sousa Oliveira

Geissiane de Moraes Marcondes²

Marianna Manes

Mariana de Souza Aranha Garcia Gomes ${ }^{1}$

Maria Martha Bernardi

Tiago Antônio de Souza ${ }^{4}$

Silvia Maria Gomes Massironi ${ }^{5}$

Claudia Madalena Cabrera Mori ${ }^{1}$
Avenida Prof. Dr. Orlando Marques de Paiva, 87, Biotério

Cidade Universitária, CEP: 05508-000

São Paulo/SP, Brasil

$\triangle$ pedrokyamamoto@gmail.com

\section{Palavras-chave}

ENU mutagênese. Camundongo mutante.

Gene Kmt2d. Síndrome de Kabuki.

\section{Keywords}

ENU mutagenesis. Mutant mouse.

Kmt2d gene. Kabuki syndrome.

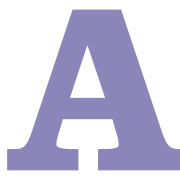

pesar dos avanços nas tecnologias moleculares, permitindo a criação de modelos murinos de doenças humanas com o emprego da manipulação direcionada do genoma, as mutações espontâneas e induzidas ainda são importantes para descoberta ou identificação de novos genes e funções. Além disso, os defeitos genéticos causados por mutações espontâneas ou induzidas podem ser semelhantes às mutações que ocorrem no genoma humano (DAVISSON et al., 2012).

ENU (N-ehtyl-N-nitrosourea) é o agente mutagênico químico mais eficaz utilizado in vivo (RUSSELL et al., 1979; PROBST; JUSTICE, 2010). As mutações pontuais induzidas por ENU têm praticamente as mesmas características das mutações espontâneas (GUÉNET, 2004, 2005). Em machos o ENU atua nas espermatogônias, agindo na forma de um agente alquilante no DNA dos camundongos, resultando em mutações pontuais (SHIBUYA; MORIMOTO, 1993; GUÉNET, 2005; GONDO et al., 2010). Tendo em vista o conhecimento adquirido sobre o potencial mutagênico apresentado por ENU, Massironi et al. (2006) investigaram a indução de novas mutações em camundongos $\mathrm{BALB} / \mathrm{c}$ e identificaram onze mutações. Entre as mutações recessivas identificadas, uma foi denominada bate-palmas (bapa), que é caracterizada pela movimentação anormal dos membros posteriores quando o camundongo é levantado pela cauda (Figura 1).

\footnotetext{
1 Universidade de São Paulo, Faculdade de Medicina Veterinária e Zootecnia, Departamento de Patologia - São Paulo, São Paulo, Brasil.

2 Universidade de São Paulo, Faculdade de Medicina Veterinária e Zootecnia, Departamento de Cirurgia -São Paulo, São Paulo, Brasil.

3 Universidade Paulista - São Paulo, São Paulo, Brasil.

4 Universidade de São Paulo, Centro de Facilidades de Apoio a Pesquisa - São Paulo, São Paulo, Brasil.

5 Universidade de São Paulo, Instituto de Ciências Biomédicas, Departamento de Imunologia - São Paulo, São Paulo, Brasil.
} 
No sequenciamento do exoma, após mapeamento genético utilizando microssatélites, foi identificada como forte candidata uma mutação no gene lysine (K)-specific methyltransferase 2D (Kmt2d, também conhecido como Mll2 ou Mll4), localizado no cromossomo 15. Essa mutação foi confirmada por sequenciamento do DNA pelo método de Sanger. O gene Kmtd 2 é uma metil-transferase que promove a trimetilação da histona $\mathrm{H} 3$ lisina $\mathrm{K} 4$ (H3K4me3), levando à abertura da cromatina e à expressão gênica (BJORNSSON et al., 2014).

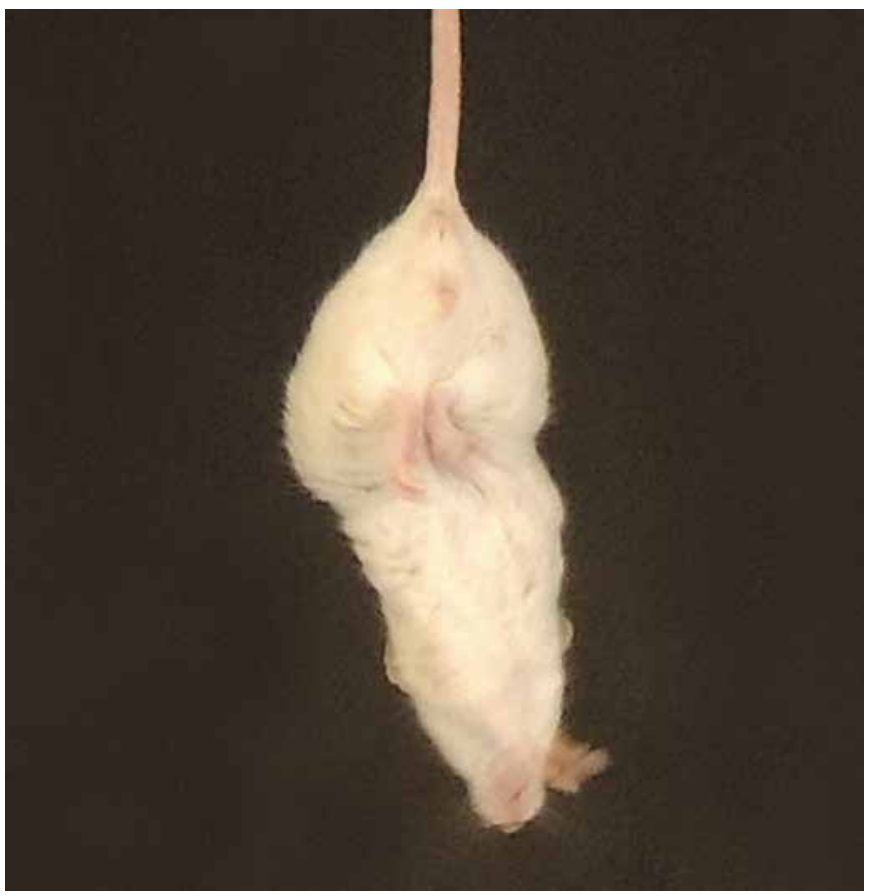

Figura 1 - Postura do camundongo bapa quando levantado pela cauda: os membros posteriores apresentam-se unidos.

Fonte: Arquivo pessoal.

Poucos modelos murinos já foram descritos para estudo do gene KMT2D, responsável pela síndrome de Kabuki em humanos. O modelo murinho Kmt2d $\mathrm{d}^{\mathrm{Gt}(\mathrm{RRT} 024)}$ Byg apresenta alterações na neurogênese, além de déficit de memória relacionada com a atividade do hipocampo; inclui a má formação craniofacial, também identificada na síndrome de Kabuki em humanos (BJORNSSON et al., 2014). Outros modelos em camundongos que apresentam perda da função de um alelo para o gene Kmt2a (Mll1) e Kmt2b (Mll2) também apresentaram alterações na memória e aprendizagem, além de alterações na plasticidade sináptica e defeitos na neurogênese, sugerindo que ambos os genes possuem funções redundantes no hipocampo (KERIMOGLU et al., 2013; SHEN et al., 2014; JAKOVCEVSKI et al., 2015).

O presente estudo foi delineado para a caracterização do fenótipo dos camundongos bapa por meio de experimentos de análise comportamental e exames radiográficos no auxílio da validação funcional como modelo de mutação do gene $\mathrm{Kmt} 2 \mathrm{~d}$.

\section{Material e métodos}

Foram utilizados camundongos machos $(\mathrm{n}=30)$ provenientes do Biotério de Camundongos do Departamento de Imunologia do Instituto de Ciências Biomédicas (ICB) e alojados por pelo menos uma semana antes do início dos experimentos no Biotério do Departamento de Patologia da Faculdade de Medicina Veterinária e Zootecnia (FMVZ), ambos da Universidade de São Paulo (USP).

Os animais foram mantidos em gaiolas de polipropileno $(30 \times 20 \times 13 \mathrm{~cm})$ forradas com cama de sabugo de milho granulado e autoclavado, trocadas uma vez por semana. As condições ambientais foram: ciclo de claro/ escuro de 12 horas, umidade relativa do ar de $55 \pm 10 \%$ e temperatura de $22 \pm 2^{\circ} \mathrm{C}$. Ração comercial para camundongos (Nuvilab CR-1, Quimtia SA) e água filtrada e autoclavada foram oferecidas ad libitum durante todo o procedimento experimental.

Todos os procedimentos experimentais foram aprovados pela Comissão de Ética no Uso de Animais da FMVZ/USP sob protocolo de número: 1004070715.

\section{Testes comportamentais}

Para os experimentos comportamentais foram utilizados camundongos com dez semanas de idade, separados em grupos experimental bapa $(\mathrm{n}=15)$ e controle BALB/c $(n=15)$.

\section{Atividade geral em campo aberto}

O campo aberto é utilizado para a observação da atividade geral dos camundongos para a caracterização quantitativa e qualitativa dos parâmetros exploratórios e motores em um ambiente novo (TATEM et al., 2014). O animal foi colocado na porção central do campo e observado durante cinco minutos (Figura 2). O tempo de locomoção e a frequência de levantar foram analisados com o programa OpenFLD.Ink (https://goo.gl/BTKeDn).

\section{Coordenação motora em trave elevada}

A trave elevada (Figura 3) foi empregada para avaliar possíveis alterações na coordenação motora de camundongos mutantes (LUONG et al., 2011). Nos dois primeiros dias, os camundongos foram treinados a andar sobre a trave em três tentativas com duração de cinco minutos cada. No terceiro dia foi realizado o teste, sendo considerada uma única tentativa de atravessar a trave. O desempenho dos camundongos no teste foi avaliado com a observação do tempo de travessia. 

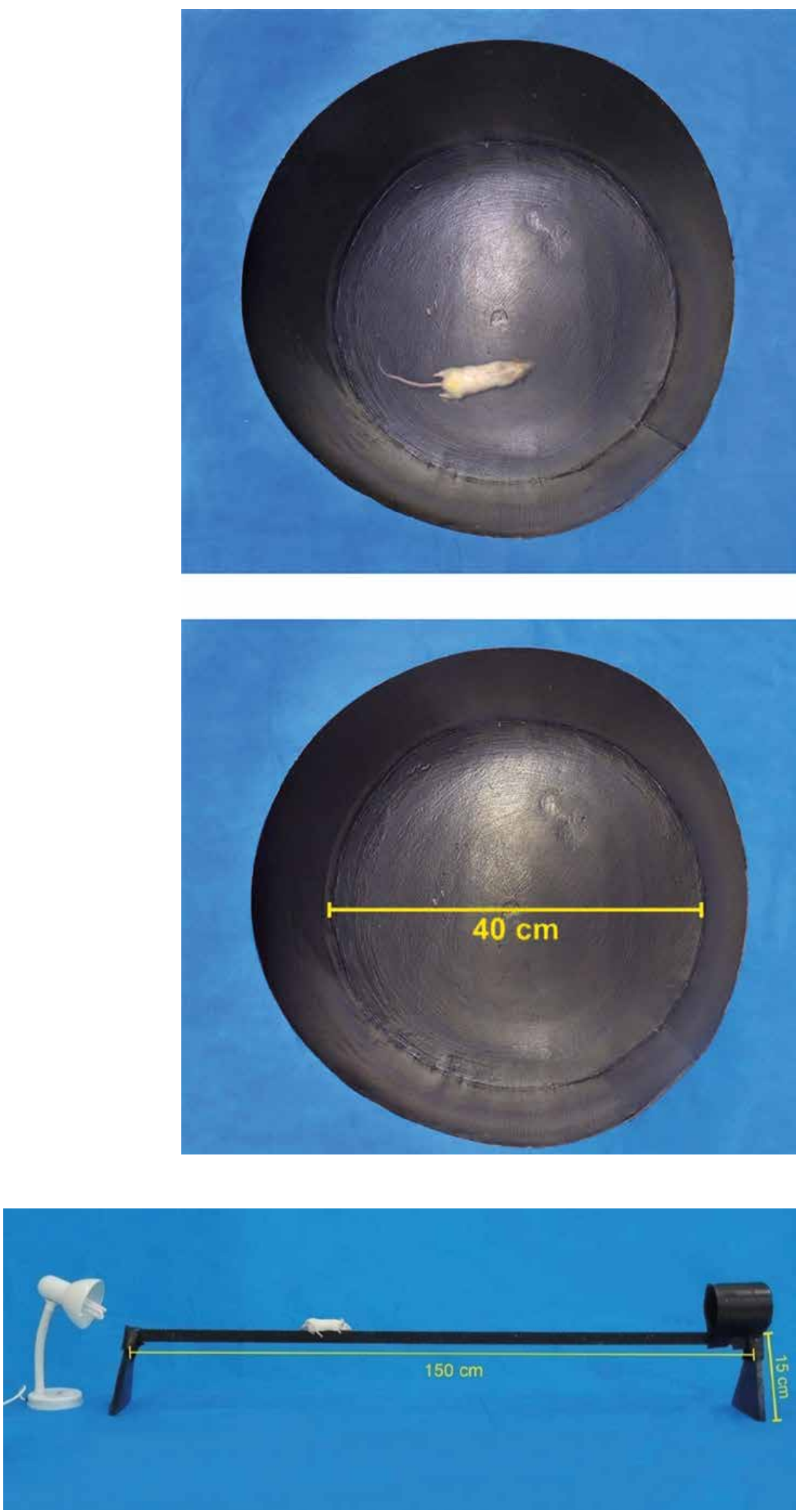

Figura 2 - Arena do campo aberto (visto de cima) em que os camundongos são colocados para observação do seu comportamento, com sua respectiva dimensão. Fonte: Oliveira, 2017

Figura 3 - Procedimento adotado para a análise do comportamento de camundongos. Trave elevada

(vista de lado) com a lâmpada no início utilizada como estímulo aversivo e, na outra extremidade, o abrigo com cama da gaiola e suas respectivas dimensões. Fonte: Oliveira, 2017 


\section{Imagens radiográficas}

Para as imagens radiográficas, foram utilizados camundongos machos bapa $(\mathrm{n}=10)$ e camundongos BALB/c $(n=10)$ com doze meses de idade. Foi utilizado um equipamento radiográfico composto pelo aparelho MinX-Ray e placa modelo Mark IIG da marca Sound Eklin com 60 $\mathrm{kV}$ e $0,9 \mathrm{mAs}$. Os animais foram anestesiados e colocados em decúbito lateral sobre a placa a uma distância de $65 \mathrm{~cm}$ do aparelho, e as tomadas, projetadas látero-lateralmente, foram efetuadas a partir de uma incisão perpendicular ao plano filme-foco. A partir das imagens, foram definidas quatro medidas (Figura 4) e foi utilizado o programa ImageJ (https://imagej.nih.gov/ij/) para a mensuração.

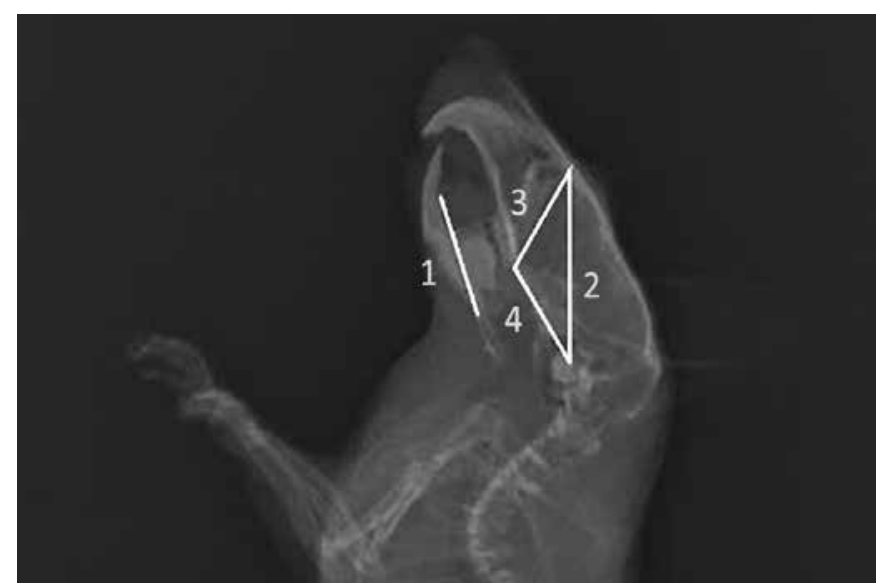

Figura 4 - Imagem radiográfica do crânio de camundongo destacando as medidas utilizadas nas análises enumeradas de 1 a 4.

Fonte: Arquivo pessoal.

\section{Análise estatística}

A análise estatística foi feita com o programa GraphPadPrism 5.03, utilizando-se o teste t student $(\mathrm{p}<0,05)$.

\section{Resultados e discussão}

O estudo de mutações em camundongos pode revelar novas funcionalidades para genes conhecidos, identificar genes subjacentes a doenças humanas ortólogas (casos em que o gene casual ainda não foi identificado) e pode proporcionar a investigação de novos fenótipos relevantes para as ciências biomédicas (DAVISSON et al., 2012). O modelo bapa com mutação localizada no gene $\mathrm{Kmt} 2 \mathrm{~d}$ apresenta alterações fenotípicas que comprometem o sistema motor. Esse gene foi relacionado com a síndrome de Kabuki, também conhecida como síndrome Niikawa-Koruki, que é uma anomalia congênita rara, autossômica dominante, caracterizada como uma mutação com perda de função no gene KMT2D, localizado no cromossomo 12 em humanos (BJORNSSON et al., 2014). O fenótipo clínico da síndrome de Kabuki é bastante variável, mas algumas características mais evidentes podem ser identificadas, tais como face dismórfica, anormalidades esqueléticas, alterações nas impressões digitais, má formação visceral, leve a moderada deficiência cognitiva e diminuição do crescimento pós-natal (MAKRYTHANASIS et al., 2013; BJORNSSON et al., 2014; SCHOTT et al., 2016). Os transcritos em camundongos e humanos apresentam 19.823 e 19.419 pares de bases e contêm 55 e 54 éxons, respectivamente. Sequências de alinhamento entre o material genético de camundongos e humanos revelou que os dois genes são $88 \%$ idênticos. As proteínas KMT2D em camundongos e humanos possuem 5588 e 5537 aminoácidos respectivamente, e ambos apresentam cerca de $600 \mathrm{kDa}$ de peso. Alinhamentos da sequência da proteína KMT2D revelaram que as duas proteínas são 90\% idênticas (FROIMCHUK; JANG; GE, 2017).

$\mathrm{Na}$ análise no teste de campo aberto, os camundongos mutantes bapa, em relação aos camundongos controle, apresentaram atividade similar. Da mesma forma, os camundongos $\mathrm{Kmt} 2 \mathrm{~d}^{\mathrm{Gt}(\mathrm{RRT} 224) \mathrm{Byg}}$ e $\mathrm{Kmt} 2 \mathrm{~d}^{+/+}$também não apresentaram déficit na atividade geral em campo aberto (BJORNSSON et al., 2014). A frequência de levantar (Figura 5) não apresentou diferença entre os grupos $(\mathrm{p}=0,1907)$.
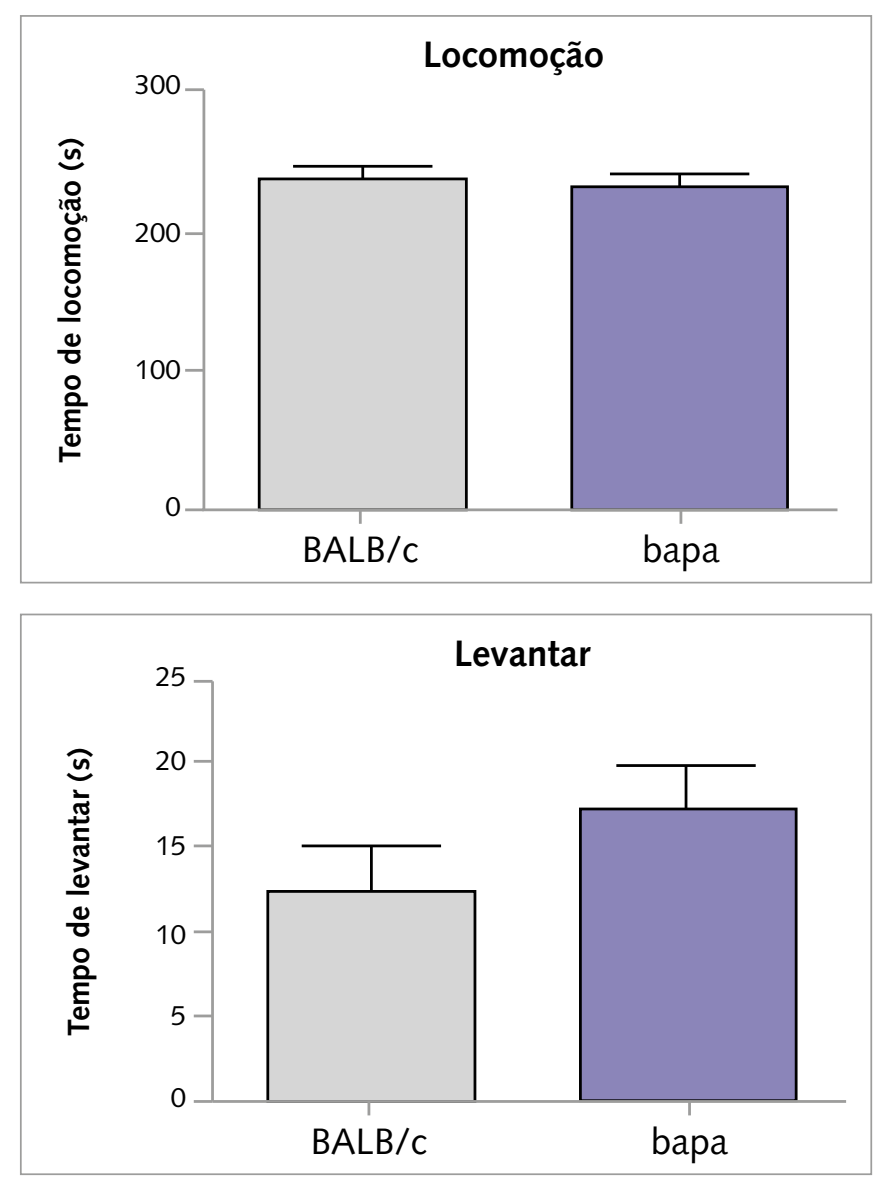

Figura 5 - Avaliação do tempo de locomoção (à esquerda) e frequência de levantar (à direita) dos camundongos bapa $(n=15)$ e BAL/c $(n=15)$ no teste de campo aberto. Fonte: Arquivo pessoal. 
O tempo de travessia da trave elevada (Figura 6) foi maior para os camundongos bapa quando comparados aos seus controles $(\mathrm{p}=0,0314)$, fenômeno que pode estar associado com o prejuízo motor descrito na literatura como uma das principais evidências da perda de função do gene Kmt2d em camundongos (BJORNSSON et al., 2014). Durante a travessia, os animais mutantes bapa apresentaram maior dificuldade de manter o equilíbrio e utilizaram a cauda como auxílio, além dos frequentes escorregões dos membros posteriores, resultando em aumento do tempo de travessia.

Nas análises radiográficas do camundongo transgênico $\mathrm{Kmt} 2 \mathrm{~d}^{\mathrm{Gt}(\mathrm{RRT} 024) \mathrm{Byg}}$ foram evidenciadas diferenças morfológicas craniofaciais (BJORNSSON et al., 2014). Diferentemente do modelo descrito na literatura, as medidas definidas da região craniofacial dos camundongos bapa não diferiram das medidas dos camundongos do grupo controle (Figura 7).

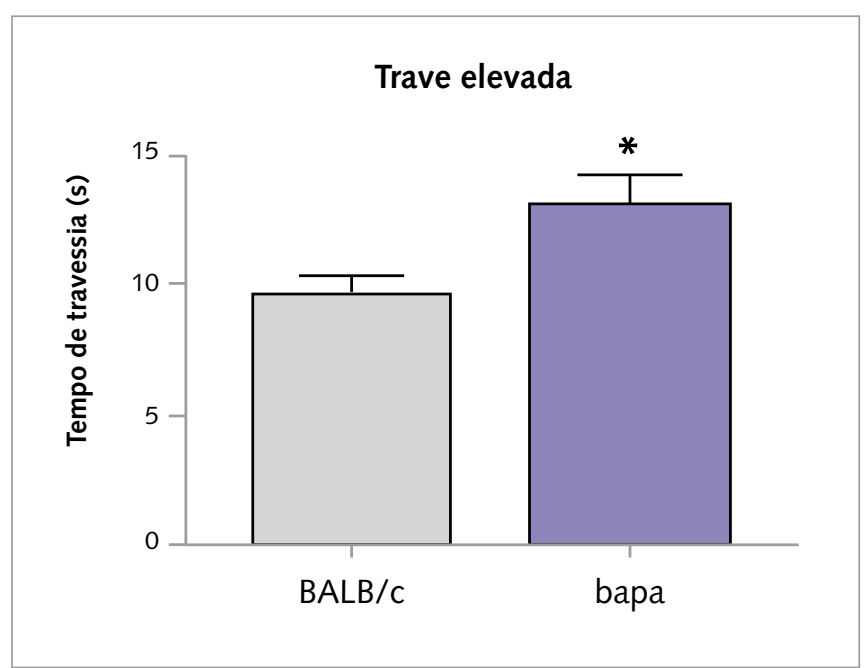

Figura 6 - Avaliação dos camundongos bate palmas $(n=15)$ e BALB/c $(n=15)$ no teste de coordenação motora observada em trave elevada.

Fonte: Arquivo pessoal.
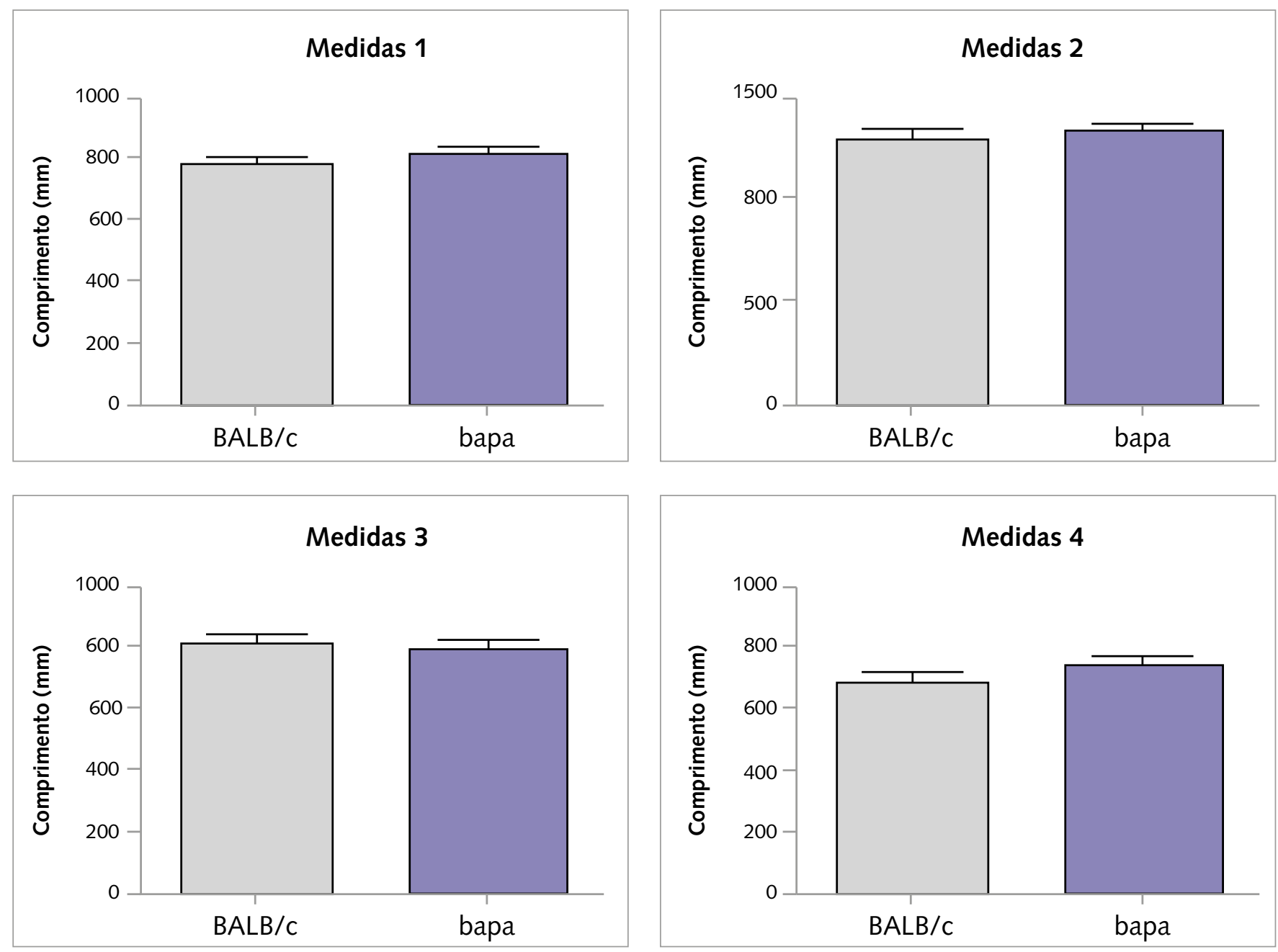

Figura 7 - Avaliação das medidas craniofaciais anteriormente estabelecidas em camundongos bapa $(n=10)$ e BALB/c $(n=10)$ nas radiografias Fonte: Arquivo pessoal. 
Os resultados obtidos evidenciam déficit motor no mutante bapa, resultado também encontrado em outros modelos murinos do mesmo gene (KERIMOGLU et al., 2013; BJORNSSON et al., 2014; SHEN et al., 2014; JAKOVCEVSKI et al., 2015). Observa-se que diferentes alelos do mesmo gene podem se expressar de forma diversa em "background" genético variado, uma vez que o modelo transgênico $\mathrm{Kmt} 2 \mathrm{~d}^{\mathrm{Gt}(\mathrm{RRT} 024) \mathrm{Byg}}$ foi estabelecido em um "background" misto entre as linhagens isogênicas 129 e C57BL/6 e, o modelo aqui descrito foi induzido em camundongos da linhagem BALB/c. Observa-se ainda que a mutação $\mathrm{Kmt} 2 \mathrm{~d}^{\mathrm{Gt}(\mathrm{RRT} 024) \mathrm{Byg}}$ é dominante, enquanto a mutação bapa é recessiva.

\section{Referências}

BJORNSSON, H. T. et al. Histone deacetylase inhibition rescues structural and functional brain deficits in a mouse model of Kabuki syndrome. Science Translational Medicine, Washington, v. 6, n. 256, p. 256ra135, 2014. Disponível em: <https://www.ncbi.nlm. nih.gov/pmc/articles/PMC4406328/pdf/nihms616530.pdf>. Acesso em: 30 jun. 2017.

DAVISSON, M. T. et al. Discovery genetics: the history and future of spontaneous mutation research. Current Protocols in Mouse Biology, Hoboken, v. 2, p. 103-118, 2012.

FROIMCHUK, E., JANG, Y., GE, K. Histone H3 lysine 4 methyltransferase KMT2D. Gene, Amsterdam, v. 627, p. 337342, 2017.

GONDO, Y. et al. ENU-based gene-driven mutagenesis in the mouse: a next-generation gene-targeting system. Experimental Animals, Tokyo, v. 59, n. 5, p. 537-548, 2010.

GUÉNET, J. L. Chemical mutagenesis of the mouse genome: an overview. Genetica, Dordrecht, v. 122, n. 1, p. 9-24, 2004.

The mouse genome. Genome Research, Cold Spring Harbor, v. 15, n. 12, p. 1729-1740, 2005.

JAKOVCEVSKI, M. Neuronal Kmt2a/Mll1 histone methyltransferase is essential for prefrontal synaptic plasticity and working memory. The Journal of Neuroscience, Washington, v. 35, n. 13, p. 5097-5108, 2015.

KERIMOGLU C. et al. Histone-methyltransferase MLL2 (KMT2B) is required for memory formation in mice. The Journal of Neuroscience, Washington, v. 33, n. 8, p. 3452-3464, 2013.
LUONG, T. N. et al. Assessment of motor balance and coordination in mice using the balance beam. Journal of Visualized Experiments, Boston, n. 49, e2376, 2011.

MAKRYTHANASIS, P. et al. MLL2 mutation detection in 86 patients with Kabuki syndrome: a genotype-phenotype study. Clinical Genetics, Copenhagen, v. 84, n. 6, p. 539-545, 2013.

MASSIRONI, S. M. et al. Inducing mutations in the mouse genome with the chemical mutagen ethylnitrosourea. Brazilian Journal of Medical Biological Research, Ribeirão Preto, v. 39, n. 9, p. 12171226, 2006.

OLIVEIRA, N. S. Caracterização fenotípica do camundongo mutante bate palmas induzido pelo agente mutagênico químico ENU (N- Ethyl- N- Nitrosourea) como potencial modelo para a síndrome de Kabuki. 2017. Dissertação (Mestrado) - Universidade de São Paulo, Faculdade de Medicina Veterinária e Zootecnia, São Paulo, 2017.

PROBST, F. J.; JUSTICE, M. J. Mouse mutagenesis with the chemical supermutagen ENU. Methods in Enzymology, New York, v. 477 , p. 297-312, 2010.

RUSSELL, W. L. et al. Specific-locus test shows ethylnitrosourea to be the most potent mutagen in the mouse. Proceedings of the National Academy of Sciences of the United States of America, Washington, v. 76, n. 11, p. 5818-5819, 1979.

SCHOTT, D. A. et al. Growth pattern in Kabuki syndrome with KMT2D mutation. American Journal of Medical Genetics. Part A, Hoboken, v. 170, n. 12, 3172-3179, 2016.

SHEN, E. et al. Regulation of histone H3K4 methylation in brain development and disease. Philosophical Transactions of the Royal Society B: Biological Sciences, v. 369, n. 1652, p. 514, 2014. Disponível em: <https://www.ncbi.nlm.nih.gov/pmc/ articles/PMC4142035/pdf/rstb20130514.pdf>. Acesso em: 30 jun. 2017.

SHIBUYA, T.; MORIMOTO, K. A review of the genotoxicity of 1-ethyl-1-nitrosourea. Mutation Research, Amsterdam, v. 297, n. 1, p. 3-38, 1993.

TATEM, K. S. et al. Behavioral and locomotor measurements using an open field activity monitoring system for skeletal muscle diseases. Journal of Visualized Experiments, Boston, v. 91, e51785, 2014. Disponível em: <https://www.ncbi.nlm.nih.gov/ pmc/articles/PMC4672952/pdf/jove-91-51785.pdf>. Acesso em: 30 jun. 2017. 